(2) Open Access Full Text Article

\title{
Asperger syndrome related suicidal behavior: two case studies
}

\author{
This article was published in the following Dove Press journal: \\ Neuropsychiatric Disease and Treatment \\ 21 November 2013 \\ Number of times this article has been viewed
}

\section{Jana Kocourkova \\ Iva Dudova \\ Jiri Koutek}

Department of Child Psychiatry, Charles University Second Faculty of Medicine, University Hospital Motol, Prague, Czech Republic
Correspondence: Jana Kocourkova Department of Child Psychiatry, Charles University Second Faculty of Medicine, University Hospital Motol, V Uvalu 84, I 5006 Prague, Czech Republic

Tel +420 224433456

Fax +420 224433420

Email jana.kocourkova@lfmotol.cuni.cz

\begin{abstract}
Asperger syndrome hinders adaptation to developmental challenges during childhood and adolescence, particularly with regard to interpersonal relationships. Individuals with Asperger syndrome display lack of empathy and limited ability to understand social and emotional exchanges with other people. Individuals with Asperger syndrome are significantly exposed to the risk of suicidal behavior, especially during adolescence. The authors describe cases of suicidal behavior in two adolescent boys with Asperger syndrome.
\end{abstract}

Keywords: Asperger syndrome, suicidal behavior, adolescence

\section{Introduction}

Asperger syndrome (AS) is a pervasive developmental disorder, characterized by impaired communication and social interaction, and by unusually intensive, narrowly specified interests, or restricted, repetitive, and stereotyped patterns of behavior, interests, and activities. People with AS are not affected by significant overall delays in speech development or cognitive development. Most individuals with AS are not diagnosed while young children. ${ }^{1}$ The average age at diagnosis is 7.2 years. ${ }^{2}$ The DSM-V Work Group has proposed removing Asperger's Disorder as a distinct category in the Diagnostic and Statistical Manual of Mental Disorders (DSM), citing a lack of evidence to distinguish it from autism, and research that suggests many, if not all, individuals with clinically significant social impairments and restricted ranges of interests and behavior would meet the newly-outlined criteria for Autism Spectrum Disorder (ASD). Despite lack of evidence that AS is a distinct condition, its existence as a separate clinical diagnosis has helped to increase our understanding of the autism spectrum. ${ }^{3}$

Social interactions in AS are marked by a biologically-based limitation in understanding others' emotions. ${ }^{3}$ Typically, people with AS are motivated to interact with others, but they become socially isolated because their style of communication is different. They behave formally, and keep a distance from others, including members of their own family. Frequently, they only turn to others to satisfy their own needs. It is difficult for them to socialize with their peers, and even more difficult for them to find a friend. They have difficulty understanding other people's needs, frequently lack empathy, and appear to be self-centered. Their capacity to express their feelings is limited. They have a tendency for underrating and condemning themselves, and they tend to look for personal shortcomings. By contrast, some display an absolute lack of criticality toward themselves; they emphasize their above-average intelligence, 
and behave inconsiderately towards family members. ${ }^{4,5}$ The ability to control behavior is reduced in individuals with AS. They are prone towards mood swings, and experience fits of anger that are difficult to control, even in older-aged individuals. Problematic behavior frequently occurs in response to changes in their routine activities. Ritualized behavior is directed towards both the self and the environment. Personal interests are narrowly focused, and of a "clinging" nature, most often relating to things where some kind of order, or repetitive elements, can be traced. It is both the intensity and the content of their interests that distinguish individuals with AS. ${ }^{4}$

Evaluation of AS must also consider both differential diagnosis and potential comorbid conditions. Unfortunately, the psychiatric conditions that most overlap with features of ASD, are also the conditions that most frequently co-occur with ASDs. These include mood and anxiety disorders, Attention Deficit Hyperactivity Disorder, and ObsessiveCompulsive Disorder. ${ }^{6}$ Psychotic disorders can also co-occur with ASDs, although this is rare. Adolescents and adults with AS can develop depression, sometimes as a result of the realization that they are unable to overcome their social difficulties unaided. ${ }^{3}$ Suicidal thoughts and behavior, atypical depression, and alcohol abuse often occur in individuals with AS. ${ }^{7}$

Suicidal behavior in children and adolescents represents a serious medical and psychosocial issue. Through suicidal actions, a patient's life can be endangered and, in cases of survival, serious medical complications can result. Suicide is the third most frequent cause of death in adolescents; adolescent age is the biggest risk factor for attempted suicide. ${ }^{8}$ An attempted suicide, potentially damaging the survivor's health, also poses a risk for repetition of the suicidal behavior. ${ }^{9}$

Suicidal behavior, as such, is not an independent condition in psychiatric diagnosis. Rather, we view it as a syndrome, which may be linked to more than one mental disease. Psychiatric and psychological examinations are necessary to assess the seriousness of attempted suicide, the presence of mental illness, and suicidal risk factors for the future.

Suicidal behavior, in some of its forms, can be linked to a row of psychiatric disorders. Most frequently, it is connected with depression. It has been suggested that affective disorder plays a part in $70 \%-80 \%$ of suicides, and that $15 \%$ of patients who have depression end their lives by suicide. Also, we often find depressive symptoms in the patients after an attempted suicide. The suicide risk of depressed children and adolescents is about 20 times greater in comparison to their healthy peers. Depressive syndromes with predominantly exogenous causes have a lower suicide risk, which, nevertheless, cannot be eliminated. Another serious mental disorder linked to suicide risk is schizophrenia. According to various studies, $2 \%-12 \%$ of schizophrenics commit suicide, and suicide risk in connection with schizophrenia is $10 \%-20 \%$ higher than in the general population. Although schizophrenia occurs most frequently in the young adult years, in $4 \%$ of cases, the first attack of the illness appears at age 15 years or younger; $10 \%$ of cases occur at ages 15-20 years. ${ }^{10}$

Regarding suicidal adolescents, we need to understand their subjective concept of death, which is affected by their ways of thinking, and experiencing emotions. We need to evaluate affective state, cognitive distortion, personality traits, the character and importance of interpersonal relations, and experience with death. Gothelf et $\mathrm{al}^{11}$ state that evaluation of the death concept is potentially valuable in the assessment of adolescents who manifest a high risk of suicide. The subjective concept of death is also affected by psychopathological aspects. With respect to AS, it is important to discover how ways of thinking and experiencing affect the concept of death and ideation of suicide, so as to establish a patient's motivation for, and the magnitude of risk for repetition of suicidal behavior.

Suicidal behavior in patients with AS represents a significant maladaptation risk. Lainhart ${ }^{12}$ states that depressive and anxiety disorders are the most frequently occurring disorders within the autistic spectrum. Shtayermman ${ }^{13}$ described a cohort of ten adolescents and young adults, half of whom had a clinically significant level of suicidal ideation. Adolescents with diagnosed AS manifest a higher risk for suicidal behavior; in particular, because of difficulties in social communication, and difficulty achieving adolescent developmental outcomes, such as attainment of autonomy, integration with a peer group, and creating an intimate relationship. Shtayermman ${ }^{14}$ points to the risk of peer victimization, and accentuates the need to investigate peer victimization, comorbid disorders, and level of suicidal ideation among these adolescents. The significance of suicidal behavior in patients with AS is emphasized also by Fitzgerald, ${ }^{15}$ who concluded that the suicide risk is much higher than was previously recognized. Raja et al $^{16}$ studied a cohort of adult suicidal patients with disorders within the autism spectrum, and described, in agreement with other authors, their developmental problems in social adaptation during childhood and adolescence. They mentioned low self-esteem, due to repeated serious social failures, feelings of isolation, and conflict between patients and their parents. Clinical 
features of suicide attempts by adults with autism spectrum disorders are also described by Kato et al. ${ }^{17}$

\section{Case study I}

A 16 year-old boy was hospitalized at the Department of Child Psychiatry, for suicidal behavior. He was transferred from an anesthesiological clinic, where he had been admitted urgently for serious drug intoxication. He had ingested tramadol and alprazolam at school, which he had brought from home and told his classmates about; the school called an ambulance. In a psychiatric interview, he described that the world makes no sense to him anymore; that he wants to kill himself because of "unhappy love"; that he thinks about the world, and justice, and believes in God; he knows that punishment awaits him for suicide, believing he would go to purgatory and would "serve his sentence" there. He fell in love with a classmate a year ago, and kept thinking about her. He was able to endure that she found someone else, but he could not bear the fact that he was disappointed in her - that she was ordinary. As he said, suicide has become the meaning of life. The boy spoke in a cultured manner, and took great pains to explain his ideas in detail. In contrast, he episodically used obscene language.

Based on the anamnestic data collected, the patient comes from a family where both his biological parents have university degrees, are religious, and have problems in their own relationship. The boy is an only child. No conspicuous signs were noted in his early development, but poor social adaptation was observed after he started school. He did not communicate much with his parents, and he had a tendency to focus upon "the problems of the world". He did well at school always, and had no behavioral problems, but he did not get along with his classmates. He sees his school years as the worst period of his life, because he had to learn about what did not interest him. He is interested in film, is well acquainted with filmography, and writes film scripts. He would like to study psychology. Neither his parents nor any expert, such as a pediatrician, teacher, or school psychologist, raised any concern about the boy's development with respect to an ASD, even though they did describe certain abnormalities in his behavior and adaptation.

Due to the gravity of the suicide attempt, and the patient's depressive nature, sertraline was administered at the anesthesiological clinic. After transfer to the psychiatric ward, the patient showed almost no critical judgment of his suicidal behavior and its connection with the relationship problems described. He exhibited very strong, even obsessive compulsions to contact his ex-girlfriend, and verbalized his continuing suicidal intentions in an urgent and nondistractible manner. In evaluating this hardly-understandable motivation for suicide, we suspected the possibility of ASD in the patient. The Childhood Autism Spectrum Test, for parents, the Autism Diagnostic Interview - Revised, and a psychological examination confirmed the diagnosis of AS. Following the diagnosis, sertraline was discontinued, and, due to the patient's persistent announcement of his suicidal intention, lithium was administered, as part of therapy, to very good effect. Structured guidance was provided through psychotherapy within individual and family settings, focusing on explanation of wrongly-understood and problematic relationship situations. The diagnosis of AS was relieving for both parents and patient, and was important for their understanding of differentness in the patient's interpersonal reactivity.

\section{Case study II}

A 16-year-old boy was hospitalized at the Department of Child Psychiatry, after ingesting a large quantity of benzodiazepine. He said he had been thinking about suicide for about one month, because he did not enjoy life; he tried to enter another world. He believes in life after death, that each person is their own God, and that suicide means nothing. In the past, he would harm himself, and cut himself with a kitchen knife or chip of glass when he was unsuccessful at school.

Anamnestic data revealed that both of the patient's parents have university degrees and value high achievement. In his early development, there was a delay in walking (with no cause identified), and his speech development was affected by dyslalia. He was always somewhat awkward in his movement. He had some difficulty adapting to children's collective environments. He had excellent results at school, but had few friends. His main interests were in encyclopedias and politics. Adaptation problems increased when he transferred to a bilingual grammar school, where he failed again to integrate with peers. At the age of 13 , he was hospitalized at a psychiatric department, for vague suicidal proclamations, and was diagnosed with AS.

During his hospitalization at the child psychiatry clinic, the patient expressed his intention to commit suicide in a pseudo-rational way. His emotions and mindset were unbalanced; his formulations concerning suicide were formally rational, but had magical and supernatural content. Ambivalent thoughts about existence and the meaning of life presented an extreme form of the usual adolescent questions. 


\section{Discussion}

Asperger syndrome is a specific developmental disorder that affects psychosocial adaptation, especially in the area of interpersonal relationships. Adolescence, in particular, is associated with intensive emotional experiences, which patients with AS are not sufficiently equipped to manage. Both patients we reviewed displayed social awkwardness, frequent lack of understanding of social context, limited abilities to engage in emotional exchanges, continuing inability to develop full relationships with peers, serious problems in potential partner relationships, and an unusual manner of verbal expression.

The first case involved an adolescent boy in psychiatric treatment after a serious suicidal attempt. Problems of social adaptation in relation to peers were identified during the previous event, when he had responded either by social withdrawal or exhibition. Serious failure of adaptation occurred only in his teens, especially in connection with his unrealistic fascination with a female classmate; he fell in love with her, but was unable to give up the relationship when the girl showed she was not interested. In his imagination, he was still involved, and had behaved inadequately. It was evident that his way of coping with an adolescent situation would lead towards an extreme solution - a serious suicidal risk. The core aspect of the problem was his inability to cope with the emotions that arose from the situation, as though he did not understand, and was unable to accept and cope with his frustration about the relationship. The clinical picture showed significant depressive symptoms. AS was only diagnosed during the patient's psychiatric hospitalization. The therapy was comprehensive; it included pharmacotherapy, individual psychotherapy, and family therapy. It was aimed at stabilizing the patient's emotional experience, reducing the suicidal risk, and helping him to cope with the traumatic relationship situation.

The other case also involved a serious suicide attempt by an adolescent boy, who was diagnosed with AS during his earlier psychiatric hospitalization. He stubbornly evaluated his atypical relations with others, his behavior, and his interests as personal norms. In the same way, he related his own suicidal behavior to himself. Unlike the former case, where the suicidal motivation was associated with relationship complications, the motivation here was unclear, and difficult to ascertain by means of therapy. The suicidal mindset followed from the core symptoms of AS. Despite the use of psychoactive drugs (sertraline, olanzapine) and intensive psychotherapeutic care, only a partial insight was achieved in the patient.
In both cases described above, the diagnosis of AS was established at adolescent age. In spite of peculiarities in development and psychosocial adaptation, neither the parents nor any experts considered ASD. The primary reason for providing psychiatric care was risk of suicide. Case studies by Spencer et $\mathrm{al}^{18}$ evidence the fact that ASDs can be also diagnosed in adult patients with suicidal behavior. Especially in suicidal adolescents, where suicidal motivation is difficult to understand and evaluate, it is important to consider ASD as part of differential diagnosis.

\section{Conclusion}

Suicidal behavior in adolescents is a serious medical and psychosocial issue. Suicidal behavior in adolescent individuals with AS typically involves a specific motivation, which arises from impaired ability to adaptively cope with relationships and problems associated with adolescence. The assessment of the risk of suicidal behavior, and the choice of effective therapeutic means, are part of good clinical practice in treating adolescents with AS.

\section{Acknowledgments}

This paper was written within the Programme for the Development of Fields of Study at Charles University (P07 Psychosocial Aspects of the Quality of Human Life), supported by the Ministry of Health, Czech Republic. Conceptual development of research: University Hospital Motol, Prague, Czech Republic 00064203.

\section{Disclosure}

The authors report no conflicts of interest in this work.

\section{References}

1. McConachie H, Le Couteur AL, Honey E. Can a diagnosis of Asperger syndrome be made in very young children with suspected autism spectrum disorder? J Autism Dev Disord. 2005;35(2):167-176.

2. Mandell DS, Novak MM, Zubritsky CD. Factors associated with age of diagnosis among children with autism spectrum disorders. Pediatrics. 2005;116(6):1480-1486.

3. Miller JN, Ozonoff S. Asperger's Syndrome. In: Hollander E, Kolevzon A, Coyle JT, editors. Textbook of Autism Spectrum Disorders. 1st ed. Arlington, VA: American Psychiatric Publishing; 2011.

4. Woodbury-Smith MR, Volkmar FR. Asperger syndrome. Eur Child Adoles Psy. 2009;18:2-11.

5. Thorova K. Poruchy autistického spektra [Autism spectrum disorders]. 1st ed. Prague: Portal; 2006.

6. Deprey L, Ozonoff S. Assessment of psychiatric conditions in autism spectrum disorders. In: Goldstein S, Naglieri J, Ozonoff S, editors. Assessment of Autism Spectrum Disorders. New York: The Guilford Press; 2009.

7. Hrdlicka M, Komarek V. Dětský autismus [Child Autism]. 1th ed. Prague: Portal; 2004.

8. Kenny C. Suicidal Children and Adolescents. 1st ed. London: Mark Allen Publishing Group; 2001. 
9. King RA, Apter A. Suicide in Children and Adolescents. 1st ed. Cambridge, UK: Cambridge University Press; 2003.

10. Kaplan HI, Sadock BJ. Synopsis of Psychiatry. 8th ed. Baltimore: Williams Wilkins; 1998.

11. Gothelf D, Apter A, Brand-Gothelf A, et al. Death Concepts in Suicidal Adolescents. J Am Acad Child Adolesc Psychiatry. 1998;37(12): 1279-1286.

12. Lainhart JE. Psychiatric problems in individuals with autism, their parents and siblings. Int Rev Psychiatr. 1999;11(4):278-298.

13. Shtayermman O. Suicidal ideation and comorbid disorders in adolescents and young adults diagnosed with Asperger's syndrome: A population at risk. J Hum Behav Soc Environ. 2008;18(3):301-328.

14. Shtayermman O. Peer victimization in adolescents and young adults diagnosed with Asperger's Syndrome: a link to depressive symptomatology, anxiety symptomatology and suicidal ideation. Issues Compr Pediatr Nurs. 2007;30(3):87-107.
15. Fitzgerald M. Suicide and Asperger's syndrome. Crisis. 2007;28(1): $1-3$.

16. Raja M, Azzoni A, Frustaci A. Autism spectrum disorders and suicidality. Clin Pract Epidemiol Ment Health. 2011;7:97-105.

17. Kato K, Mikami K, Akama F. Clinical features of suicide attempts in adults with autism spectrum disorders. Gen Hosp Psychiat. 2013;35: $50-53$.

18. Spencer L, Lyketsos CG, Samstad E, Dokey A, Rostov D, Chisolm MS. A suicidal adult in crisis: an unxepected diagnosis of autism spectrum disorder. Am J Psychiatry. 2011;168(9):890-892.

\section{Publish your work in this journal}

Neuropsychiatric Disease and Treatment is an international, peerreviewed journal of clinical therapeutics and pharmacology focusing on concise rapid reporting of clinical or pre-clinical studies on a range of neuropsychiatric and neurological disorders. This journal is indexed on PubMed Central, the 'PsycINFO' database and CAS.
The manuscript management system is completely online and includes a very quick and fair peer-review system, which is all easy to use. Visit http://www.dovepress.com/testimonials.php to read real quotes from published authors.

Submit your manuscript here: http://www.dovepress.com/neuropsychiatric-disease-and-treatment-journal 